\title{
Blade Number Effect for A Horizontal Axis River Current Turbine at A Low Velocity Condition Utilizing A Parametric Study with Mathematical Model of Blade Element Momentum
}

\author{
Ridway Balaka, Aditya Rachman, and Jenny Delly
}

\begin{abstract}
The power system using the clean decentralized renewable horizontal axis river current turbine can be an alternative option in delivering locally and sustainably the energies for the communities inaccessible to the electricity connection. One of the important aspects in the technology design is the selection of the blade number. This aspects can raise several consequences including the performance, the manufacturing cost and the construction constrain. The performance must be on the top of the priority in the technology design as the river velocity is typically low which effortlessly brings the technology uneconomically attractive. This study deals with the investigation of effect of the blade number on the performance of the horizontal axis river turbine for low speed condition. The investigation is conducted by a parametric study with the mathematical model of the Blade Element Momentum. The results indicate that turbines with high blade number deliver a better performance than those with the lower blade number. However, the consequences will be the low rotation for the high bladed turbines thus requiring a high gearing ratio for the mechanical transmission. This study also discusses the reason for the results of the investigation and presents a recommendation for designing of the river turbine for such low speed condition in relation to the decision of the blade number.
\end{abstract}

Index Terms-Low velocity, river turbine, blade number, performance

\section{INTRODUCTION}

It is inevitable that energies play important role in enhancing the economic development and the living standard Unfortunately, many communities, especially whom live in rural areas still have a difficulty in accessing them. The topography and geography conditions of the regions and the limited infrastructure are believed to contribute for the difficulty in accessing the energy for the communities [1], [2].

A river current turbine is one of the clean decentralized renewable energy technologies potential in delivering energy in regions where topography and geography conditions become main obstacles for the centralized power distribution system. This technology is an electromechanical energy converter that harnesses the kinetic energy of the water current of a river. It operates at almost a zero potential head that requires little or no civil work and causes less environmental impacts compared to the conventional water power technologies [3].

Manuscript received October 9, 2012; revised June 18, 2013

The authors are with Mechanical Engineering Department of Haluoleo University Kendari Indonesia (e-mail: bridway@yahoo.com.au; aditya_rchmn@yahoo.com; jennydelly@yahoo.com)
A rotor is one of the important elements in the turbine which needs a high attention in a design phase. This is because that the rotor is the only element that intercepts the moving water energy and converts it into a rotational force to drive a generator in order to produce a power.

The most common rotor configuration is horizontal and vertical axis turbine arrangements. The horizontal axis rotor is believed to deliver some beneficial features over its counterparts, the vertical turbine, including high efficiency, easy self-starting, lacks of torque fluctuation and high speed operation [4]. Studies in [3], [5] show that the horizontal axis river current turbines for the power generation have been in a stage of field experiments and field applications in some countries such as Sudan, Bangladesh, Egypt, Sudan, Somalia, Australia and South America and the United States.

One of the constraints for the turbine power application is the low typical river current velocity. This possibly brings the option of the turbine utilization to be less favorable for the implementation. This is because that the performance which is a function of the cubic velocity, for such speed condition is highly possibly low, resulting in an uneconomical technology application. In eliminating the undesirable impact of this velocity constraint on the technology application, the turbine requires to be designed as such it have a high performance on the low water speed condition.

The knowledge on the behavior on the effect of the design parameters on the performance on the river technology can assist designers when making decisions on the stage of technology design in order to obtain the technology with desirable economical sense. This study aims to investigate the effect of blade number, one of the design parameters, on the performance of a horizontal axis river current turbine at the low speed condition.

\section{LITERATURE STUDY}

Literatures which present the relation of blade number on the horizontal axis turbines performance in wind domain can be found in [6]- [9]. Most of the studies indicate that the turbine with high blade number may obtain high performance at a low rotation, while those with lower blade number may derive the high performance at a high rotation. Literature in [10] explains that the increasing on the blade number of the turbine can increase the turbine performance. But, putting too many blades may result in an aerodynamic complication, reducing the performance. According to [11], the high bladed turbines can create a blockade effect, making the decreasing 
of the mass flow rate through the rotor, thus reducing the performance. According to [12] the turbine with very high blade number may result in the reduction on the performance caused by the stall looses.

Even some of previous references show the relation of the blade number to the turbine performance; these seem to be less representative as references for the case of the water turbine as the density of both fluids is different. This difference highly possibly influences the differences on the force acting on the blade, so does the performance.

Studies in [13]- [16] show several projects on horizontal axis hydrokinetic technologies, such as tidal and river turbine, by several companies such as Verdant Power, Seaflow and several institutions such as the Harbin Engineering University, Northeast Normal University, Charles Darwin University and Brasilia University. Some of these references figure the detail of the blade number put on the turbine system. But, it seems that no detail on the investigation on the effect of the variation of the blade number on the turbine performance can be found in these references.

Literature in [5] shows some works in on the experiments on the horizontal river turbine intended for remote community application in some countries, such as Australia, United Kingdom and South America. Each of the work is conducted in different blade number. However this information seems to be less representative in delivering a figure on the effect as the blade number on the water turbine performance since the velocity condition and the blade geometry and dimension are different among the works.

\section{Methodology}

The investigation is conducted by a parametric study with the mathematical model of the Blade Element Momentum theory

\section{A. The Blade Element Momentum Model}

According to [17], this model can be utilized in designing the turbine blade and in evaluating the wind turbine performance. Using this model, it is also possible to evaluate the forces acting on the blades, the torque and the power at a rotor shaft with a wide range of wind velocities.

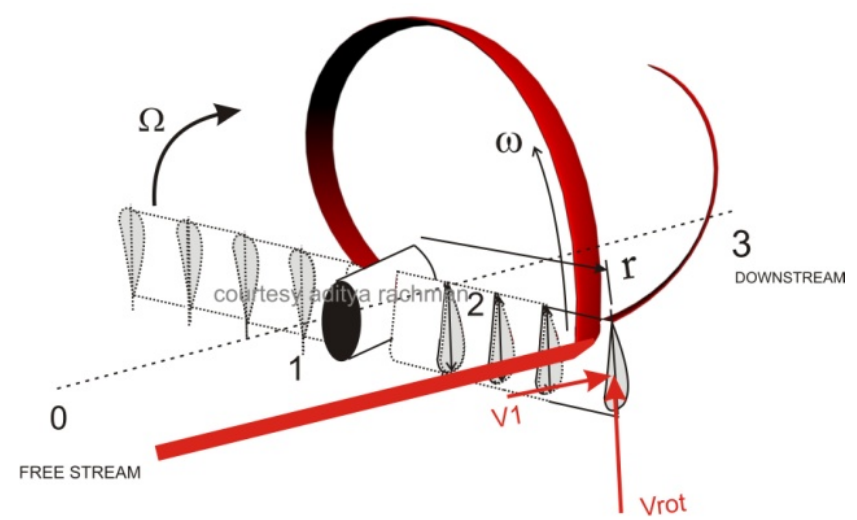

Fig. 1(a). The Blade Element Momentum model Illustrated by Rachman, adopted from [12], [21], [22]

There are similarities in the working principles between the current turbines and wind turbines [18]. The reason may come as the water current turbine is purely extracting the kinetic energy of the water with almost zero differential potential head, a similar mechanism to that of the wind turbine. According to [13], [19], the valid equation of water current turbine is analogous to that of the wind turbine. According to [20], the Blade Element Momentum model can be applied into water current domain as the basic equations which construct the model can be applied into water.

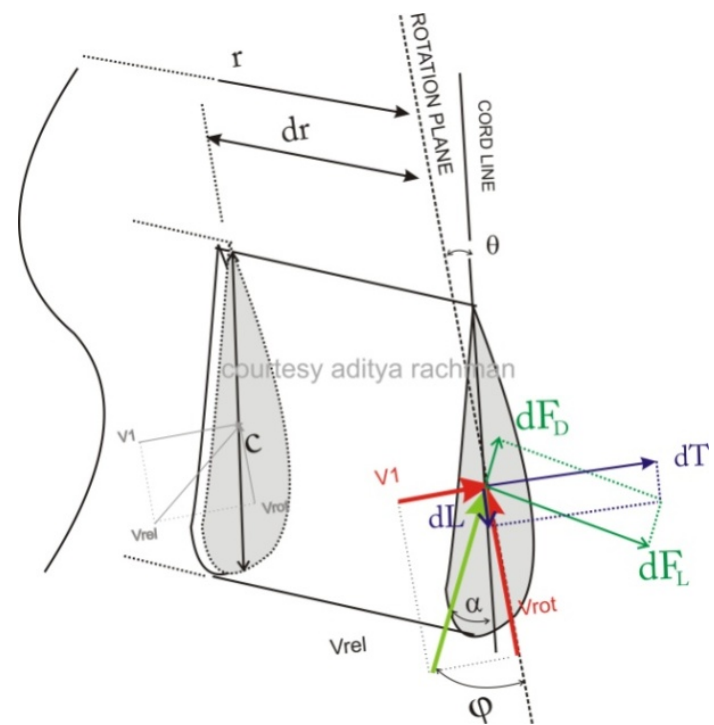

Fig. 1 (b). The detail of the forces on a blade element Illustrated by Rachman, adopted from adopted from [12], [21], [22]

In this model, the coefficient of performance (CP) (the hydrodynamic efficiency ) is formulated by

$$
\mathrm{CP}=\frac{\int_{\mathrm{rh}}^{\mathrm{R}} \Omega \mathrm{dQ}}{0.5 \rho \mathrm{A} \mathrm{V}_{0}{ }^{3}}
$$

where $\mathrm{R}$ is the turbine radius ( $\mathrm{m}$ ), $\mathrm{rh}$ is the hub radius, $\Omega$ is the turbine rotation (RPM), Vo is the ambient water velocity $(\mathrm{m} / \mathrm{s}), \rho$ is the specific mass of water $\left(\mathrm{Kg} / \mathrm{m}^{3}\right)$ and $\mathrm{A}$ is the rotor swept area $\left(\mathrm{m}^{2}\right)$ and $\mathrm{dQ}$ is the elemental torque formulated by

$$
\mathrm{dQ}=\mathrm{rdL}
$$

where $r$ is the elemental blade radius $(\mathrm{m})$ and $\mathrm{dL}$ is the elemental lift force $(\mathrm{N})$, formulated by

$$
\mathrm{dL}=\mathrm{B} \frac{1}{2} \rho \mathrm{V}_{\mathrm{rel}}^{2}\left(\mathrm{C}_{\mathrm{L}} \sin \varphi-\mathrm{C}_{\mathrm{D}} \cos \varphi\right) \mathrm{cdr}
$$

where, B is the blade number, $\mathrm{c}$ is the blade cord length $(\mathrm{m})$, $\mathrm{C}_{\mathrm{L}}$ is the lift coefficient of hydrofoil, $\mathrm{C}_{\mathrm{D}}$ is the drag coefficient of hydrofoil and $\mathrm{V}_{\text {rel }}$ is the relative velocity $(\mathrm{m} / \mathrm{s})$. Parameter of $\varphi$ is the relative angle $\left({ }^{\circ}\right)$ follows the relation of $\varphi=\alpha+\theta$, where $\theta$ is the blade angle (pitch angle) and $\alpha$ is the attack angle. The relative wind angle $(\varphi)$, also follows the relation of

$$
\varphi=\arctan \left(\frac{\mathrm{v}_{1}}{\mathrm{v}_{\text {rot }}}\right)
$$

where $V_{1}$ is the water velocity at rotor $(\mathrm{m} / \mathrm{s})$ and $V_{\text {rot }}$ is the water rotational velocity $(\mathrm{m} / \mathrm{s})$.

\section{B. The Data of Investigation}

In this investigation, the radius $(\mathrm{R})$ of the turbine is 0.5 
meter and the hub radius ( $\mathrm{rh}$ ) is $0.2 \mathrm{~m}$. The cross section of the blades has a hydrofoil shape with the type of NACA 0012 The data of the lift and drag coefficients $\left(C_{L}\right.$ and $\left.C_{D}\right)$ for this hydrofoil is derived from the study in [23]. The cord length (C) is $0.1 \mathrm{~m}$ and is constant over the blade span (non tapered). The blade angle $(\theta)$ is $0^{\circ}$ and is constant along the blade radius. The water velocity $\left(\mathrm{V}_{0}\right)$ is set to be $1 \mathrm{~m} / \mathrm{s}$. The turbine rotation $(\Omega)$ is varied form $0-90$ Rotation per Minute (RPM).

The result of this investigation is presented in a graph which shows the turbine performance, represented by the coefficient of performance $(\mathrm{CP})$ on the variation of rotation and blade number. To derive additional information that can be utilized to explain the reasons behind the results of the investigation, the data of lift force (L), attack angle $(\alpha)$ and velocity at rotor $\left(\mathrm{V}_{1}\right)$ is also calculated. This data is derived from the calculation in the investigation using the model.

To do the calculation using the Blade Element Momentum theory, the program of MATLAB is utilized.

\section{RESUlTS AND DisCUSSION}

The Fig. 3-5 are the results of the investigation; the coefficient of performance (CP), the lift force (L), the attack angle $(\alpha)$ and the velocity at rotor $\left(V_{1}\right)$ at water velocity $\left(V_{0}\right)$ of $1 \mathrm{~m} / \mathrm{s}$ in the variation of the blade number (B).

\section{A. Performance}

The turbine with 12 blades reaches its peak performance at 0.275 at rotation of $35 \mathrm{RPM}$. When the rotation is increased, the turbine starts decreasing its performance, while those with lower blade number perform better (see Fig. 2 for detail).

The results also indicate that the high bladed turbines reach the maximum efficiency at a higher value than the value at which the maximum efficiency is achieved by the lower bladed turbines.

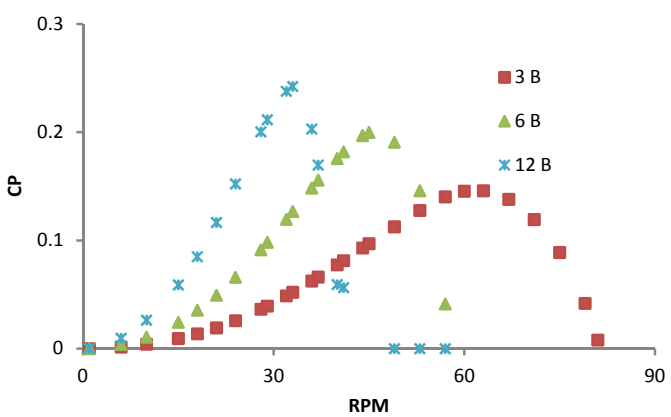

Fig. 2. The coefficient of performance in variation of the blade number at $\mathrm{V}_{0}$ $1 \mathrm{~m} / \mathrm{s}$

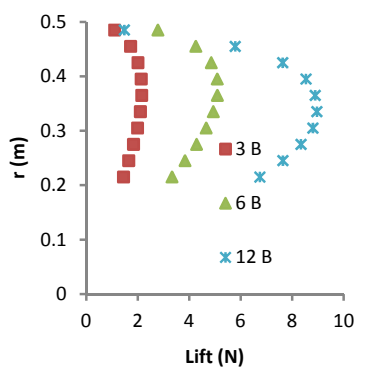

(a)

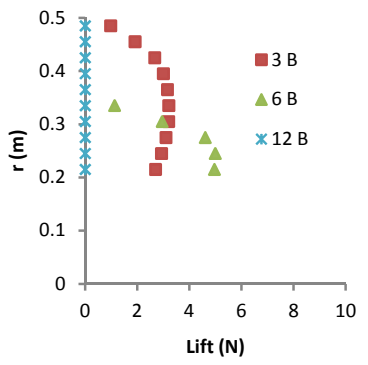

(b)
Fig. 3. (a) The force acting along blade in variation blade number a) at $35 \mathrm{~b})$ at $60 \mathrm{RPM}$

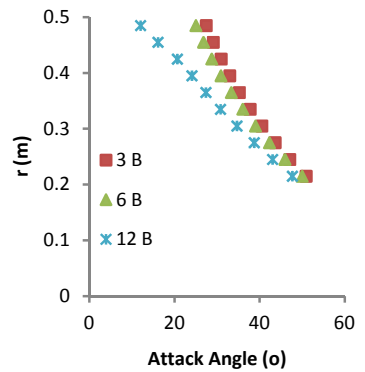

(a)

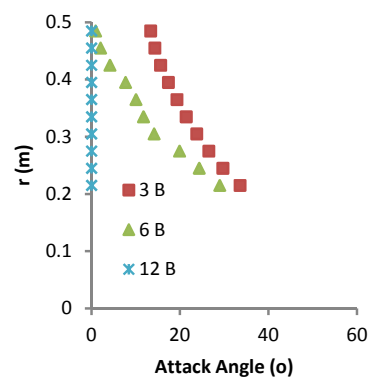

(b)
Fig, 4. (a) The attack angle acting along blade in variation blade number a) at $35 \mathrm{RPM}$ b) at $60 \mathrm{RPM}$

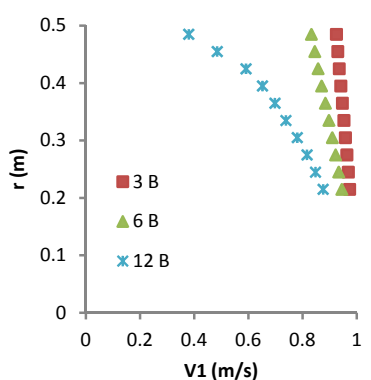

(a)

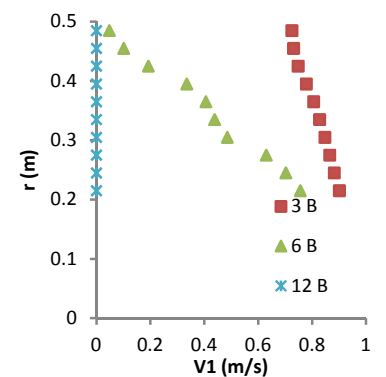

(b)
Fig. 5. (a) The velocity at rotor along blade in variation blade number a) at $35 \mathrm{RPM}$ b ) at $60 \mathrm{RPM}$

\section{B. Lift Force}

At low rotation the lift force acting along the blade for the high bladed turbine is relatively higher compared to that with the lower bladed turbine (see Fig. 3a). The reason may come as the interaction of the blade area and the wind is high as a result of the high blade number. This high force increases the torque in the blade, thus enhancing the performance. This is the reason for the high performance of the high bladed turbines at a low rotation.

At a high rotation, the lift force acting on the blade for the high bladed turbines is lower than those with lower number. It can be seen from Fig. $3 \mathrm{~b}$, that the turbine with 12 blades almost produces zero lift along its radius while those with lower blade number can still maintain its lift force along the radius. This can be the reason why the performance of the low bladed turbines is higher than those with higher number at the high rotation.

\section{Attack Angle}

As seen in Fig. 3b, at the high rotation, the lift force acting on the blade for the high bladed turbines is much lower. The attack angle may contribute to this phenomenon. This can be explained that at a high rotation for high bladed turbines, there is a tendency that the attack angle to be much lower (almost zero along the blade) than those with the lower bladed turbine (see Fig. 4b). This low attack angle results in low lift coefficient thus the lift force will be low. This condition exists as the characteristic of the hydrofoil of NACA 0012 has the low lift coefficient at very low attack angle.

\section{The relation of attack angle to the blade number}

From the phenomena of the low attack angle at the high rotation operation for the high bladed turbines, the following paragraph attempts to explain the relation to the effect of the 
blade number.

At high rotation, the velocity at rotor of the high bladed turbines is considerably lower than those with the lower blade number (see Fig. 5b). According to the explanation in the Blade Element theory in previous section, the relative angle, which is the sum of the attack angle and the blade angle, is the function of the velocity at rotor and the rotational velocity (see Equation 4). The combination of the high rotational velocity and the low rotor velocity highly possibly results in the low relative angle. As the angle is low, the attack angle will also be low (Fig. 6 and Fig. 7 illustrate the condition of the attack angle at high-low rotation for both high and low blade number turbines).

The reason for the low rotor velocity at high rotation for the high bladed turbines can be the resistance effect created by the area of the blade interacted with the fluid. For the low bladed turbine as the area interaction is less. Thus, it creates less blockade effect. As a result, the velocity at rotor is still maintained at a relatively high value at the high rotation operation.

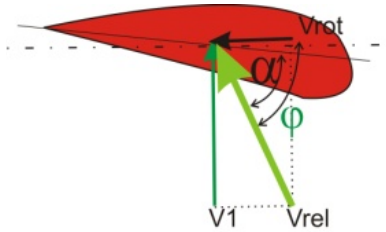

LOW ROTATION

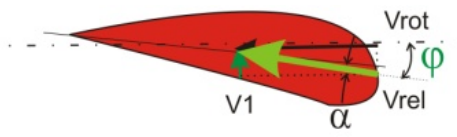

HIGH ROTATION
Fig. 6. The illustration on condition of the attack angle on a cross sectional blade area in high and low rotation for high blade number turbine

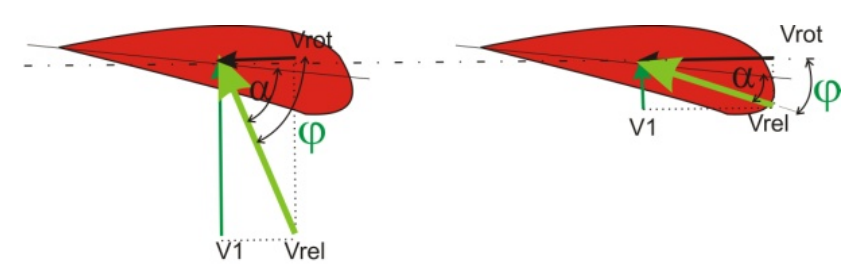

LOW ROTATION

HIGH ROTATION

Fig. 7. The illustration on condition of the attack angle on a cross sectional blade area in high and low rotation for low blade number turbine

\section{CONCLUSION AND RECOMMENDATION}

The high bladed turbines have the higher performance than those with lower number. However, the consequence will be the low rotation operation for the high bladed turbines.

This condition exists as at a low rotation the lift force acting on the blade is high as a result of high area interaction for the turbines with high blade number. At a high rotation, even the area interaction is high; the attack angle is very low. This causes a low lift coefficient thus creating low lift force, resulting in low torque generated. The reason for the low attack angle at the high rotation for the turbine with high blade number is that the velocity at rotor is low as a result of the blockade effect of the high bladed turbine. This low velocity in high rotational velocity results in low relative angle. As the angle is low the attach angle will be low.

The high performance of the high bladed turbine at a low rotation operation requires a high gearing ratio for the mechanical transmission system. As the high ratio, it possibly requires more level transmission. This may result in the high loses thus possibly reducing overall turbine system performance. Thus, it can be dilemmatic to choose the high bladed turbines in order to gain high turbine efficiency, but the consequence will be the high loses in transmission system caused by the high ratio as a result of low rotation. Thus, in designing the turbine system it requires creating a synergy between the chosen of the blade number and its corresponding rotation; as such it yields into the maximum overall turbine system performance.

\section{ACKNOWLEDGEMENT}

In presenting the mathematical model, it refers to [12], [20]-[22].

\section{REFERENCES}

[1] A. S Dasuki, M. Djamin, and A.Y. Lubis, "The strategy of photovoltaic technology development in Indonesia," The Agency for the Assessment and Application of Technology (BPPT), Indonesia, Renewable Energy, 2001

[2] A . Zahnd and H.M Kimber, "Benefits from a renewable energy village electrification system," Renewable Energy, vol. 34, pp. 362-368, 2009.

[3] M. J. Khan, M. T. Iqbal, and J. E. Quaicoe, "River current energy conversion systems: Progress, prospects and challenges," Renewable and Sustainable Energy Reviews, 12, 2008, pp. 2177-2193, Faculty of Engineering \& Applied Science, Memorial University, St. John's, A1B3X5, NL, CanadA

[4] M. J. Khan, G. Bhuyan, M. T. Iqbal, and J. E. Quaicoe, "Hydrokinetic energy conversion systems and assessment of horizontal and vertical axis turbines for river and tidal applications: A technology status review," Journal of Applied Energy, vol. 86 pp. 1823-1835, 2009.

[5] M. Anyi and B. Kirke, "Evaluation of small axial flow hydrokinetic turbines for remote communities," Energy for Sustainable Development, vol. 14, pp. 110-116, 2010.

[6] S. Atmadi and A. J. Fitroh, "Analisis dan Optimasi Sudu SKEA 5 KW untuk Pemompaan," Jurnal Teknologi Dirgantara, vol 8, no. 2, Desember 2010, pp.108-115

[7] Y Nishizawa. An Experimental Study of the Shapes of Rotor for Horizontal-Axis Small Wind Turbines. Wind Turbines, (2011), Ibrahim Al-Bahadly (Ed.), InTech. [Online]. Available: http://www.intechopen.com/articles/show/title/an-experimental-studyof-the-shapes-of-rotor-for-horizontal-axis-small-wind-turbines

[8] A. Rachman, "Parametric Study of a Horizontal Axis Ducted Wind Turbine," Master Engineering Thesis, University of Wollongong, Faculty of Engineering. NSW Australia, 2010

[9] J. Swanson and K. Visser. Improving the Efficiency of Small Wind Turbines by Optimizing Blade Number and Solidity. (2002). [Online]. Available:

http://www.clarkson.edu/reu/archives/2002/abstracts/Swanson.pdf

[10] E. Hau, Wind Turbines, Fundamentals, Technologies, Application, Economics, Springer Verlag, Berlin, 2000

[11] S. H. Wang and S. H. Cheng, "Blade number effect for a ducted wind turbine," Journal Mechanical Science Technology, vol. 22 / 198, 2008.

[12] T. Burton, D. Sharpe, N. Jenkins, and E. Bossanyi, Wind Energy Handbook, John Wiley \& Sons, Ltd Baffins Lane, Chichester West Sussex, PO19 1UD, England, 2001

[13] M. S. Guney and K. Kaygusuz, "Hydrokinetic energy conversion systems: A technology status review," In Journal of Renewable and Sustainable Energy Reviews. 2010, Article in Press, www.elsevier.com/locate/rser

[14] D. Li, S. Wang, and P. Yuan, "An overview of development of tidal current in China: Energy resource, conversion technology and opportunities," Renewable and Sustainable Energy Reviews, 2010, Article in Press, www.elsevier.com/locate/rser

[15] F. O. Rourke, F. Boyle, and A. Reynolds, " Marine current energy devices: Current status and possible future applications in Ireland ," Renewable and Sustainable Energy Reviews, vol. 14, 2010, pp.1026-1036.

[16] K. Sornes. Small-scale Water Current Turbines for River Applications. (2010). [Online]. Available: http://www.zero.no/publikasjoner/small-scale-water-current-turbines-f or-river-applications.pdf

[17] R. Lanzafame and M. Messina, "Horizontal axis wind turbine 
working at maximum power coefficient continuously," Journal Renewable Energy, vol. 35, pp. 301-306, 2010.

[18] Y. Li and S. M. Sander, "Numerical analysis of the characteristics of vertical axis tidal current turbines," Journal of Renewable Energy, 2010.

[19] R. H. Clark, Elements of tidal-electric engineering, 2007, Wiley-IEEE Press.

[20] A. Rachman, R. Balaka and J. Delly, "A mathematical model for predicting the performance of a horizontal axis river current turbine with consideration of the Blade Parameters," in Proc. International Conference and Exhibition Sustainable Energy and Advanced material 2011 (ICESEAM 2011), 3-4 October 2011, pp. 66.

[21] S. Duran, Computer-aided design of horizontal-axis wind turbine blades. Master's thesis, 2005,Middle East Technical University, Ankara, Turkey. [Online]. Available: http://iats09.karabuk.edu.tr/press/bildiriler pdf/IATS09 06-01_1290.pdf

[22] J. F. Manwell, J. G. McGowan and A. L. Rogers, "Wind Energy Explained; Theory, Design and Application," University of Massachusetts, Amherst, 2002, USA JOHN WLEY \& SONS, LTD.

[23] Sutrisno. Lift and drag characteristics of hydrofoils with different dihedral angle. Forum Teknik. Jilid 19 No 2. (Agustus 1995). [Online]. Available: i-lib.ugm.ac.id/jurnal/download.php?dataId=106

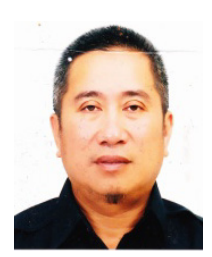

Ridway Balaka was born in Kendari Indonesia in 1959 $\mathrm{He}$ has received his Bachelor of Mechanical Engineering degree from Hassanudin University Indonesia in 1986 and his Master Engineering from Asian Institute University Thailand in 1993.

$\mathrm{He}$ is a senior lecturer in Mechanical Engineering Department of Haluoleo University Indonesia. He is interested in the research relating to the development of river current energy technology and the energy policy. He has published some papers relating to renewable river energy technologies and energy policy in several national and international conferences.

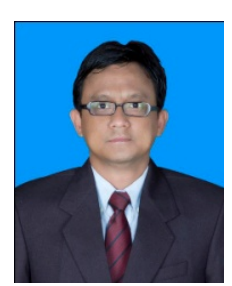

Aditya Rachman was born in Surakarta Indonesia in 1979. He has received his Mechanical Bachelor degree from Gadjah Mada University Indonesia in 2003 and his Master Engineering degree from the Engineering Faculty of Wollongong University Australia in 2010.

$\mathrm{He}$ is a lecturer in Mechanical Engineering Department of Haluoleo University Indonesia. He is interested in the research relating to development of wind energy technology. He has published some papers in several national and international conferences.

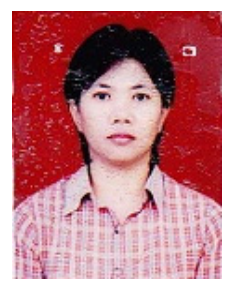

Jenny Delly was born in Kendari Indonesia in 1972. She has received her Mechanical Bachelor degree from Hassanudin University Indonesia in 1998 and her Master Engineering degree from Institut Teknologi Sepuluh November (ITS) University Indonesia in 2005.

She is a senior lecturer in Mechanical Engineering Department of Haluoleo University Indonesia. He is interested in the research relating fluid dynamic and cavitations. She has published some papers in several national and international conferences. 